\title{
ESTRATÉGIAS DE PODER DE GESTORES INTERMEDIÁRIOS NO BRASIL
}

\author{
POWER STRATEGIES OF MIDDLE MANAGERS IN BRAZIL
}

\author{
Recebido em 22.06.2016. Aprovado em 20.10.2016 \\ Avaliado pelo sistema double blind review \\ DOI: http://dx.doi.org/10.12712/rpca.v10i4.779
}

\section{Marco Antonio Bastoni}

marco.bastoni@vpar.com.br

Votorantim Investimentos Industriais S.A.

\section{Maria Jose Tonelli}

maria.jose.tonelli@fgv.br

Escola de Administração de Empresas de São Paulo da Fundação Getulio Vargas (FGV/EAESP), São Paulo/SP, BRASIL

\section{Andre Luis Silva}

andre.fgvsp@gmail.com

Escola de Administração de Empresas de São Paulo da Fundação Getulio Vargas (FGV/EAESP), São Paulo/SP, BRASIL

\section{Resumo}

Os gestores intermediários têm sido responsáveis, desde o inicio da industrialização, pela formação da classe média no Brasil. A perda do trabalho representa uma grande ameaça a esse grupo social, ao impactar a continuidade de uma condição econômica e social privilegiada num país desigual, como o Brasil. O objetivo desta pesquisa qualitativa, teórico-empírica, é discutir as estratégias de sobrevivência usadas por gestores intermediários em contexto organizacional. A base empírica de dados decorre de entrevistas em profundidade com quinze gestores intermediários atuantes em uma multinacional brasileira; uma empresa de capital misto luso-espanhol-brasileiro; e uma multinacional norte-americana. Conclui-se que os gestores intermediários se utilizam de várias estratégias de poder, sendo patente o surgimento de redes de relacionamento informais, que são poderosas, por colocarem em ação regras e políticas corporativas que estabelecem relacionamentos extracompanhia fortalecido pela troca de "favores".

Palavras-chave: Gestores intermediários. Estratégias de poder. Trabalho. Mudança organizacional.

\begin{abstract}
The middle managers have been responsible, since the beginning of industrialization, the formation of the middle class in Brazil. The job loss is a major threat to this social group, to impact the continuity of a privileged economic and social condition in an unequal country, as Brazil. The purpose of this qualitative research, theoretical and empirical, is to discuss survival strategies used by middle managers in organizations. The empirical basis of data results from in-depth interviews with fifteen active middle managers in a multinational company; a mixed capital Luso-Spanish-Brazilian company; and a US multinational. It is concluded that the interim managers use various strategies of power, and illustrates the emergence of informal social networks, which are powerful, for putting into action rules and corporate policies that establish out the companies relationships strengthened by the exchange of "favors".
\end{abstract}

Keywords: Middle managers. Power strategies. Work. Organizational change. 


\section{Introdução}

A profunda recessão de 1973, exacerbada pelo choque do petróleo, teve como consequência um conturbado período de reestruturação econômica e de reajustamento social e político, nas décadas de 1970 e 1980. Diante da forte volatilidade do mercado, do aumento da competição e do estreitamento das margens de lucro, houve a redução do emprego regular em favor do crescente uso do trabalho em tempo parcial, temporário ou subcontratado (WOOD, 1989; TACHIZAWA; FERREIRA; FORTUNA, 2006; BARLEY; KUNDA, 2006). Em países de terceiro mundo estas mudanças aconteceram de modo ainda mais violento, com altas taxas de desemprego, que levaram trabalhadores de todas as posições hierárquicas para a informalidade, ou seja, um mercado instável, inseguro e desprovido de benefícios (GITAHY, 1994; RUAS, 1994; DEDECCA, 2006; ANTUNES, 2011). Além disso, as empresas sofreram profundas transformações, com fusões, aquisições, achatamentos na hierarquia, entre outros fenômenos organizacionais vistos no período (HARVEY, 1992; FREITAS, 1999; CALDAS, 2000; WOOD JR, 2004; KREMER; FARIA, 2005).

A literatura nacional e internacional tem discutido os impactos destas transformações no mercado de trabalho e na estrutura organizacional (IANNI, 1994; KALLEBERG, 2000; LEE; TEO, 2005; BADHAM, 2006; ANTUNES, 2010; AZEVEDO; TONELLI; SILVA, 2015). Mas chama atenção que os impactos dessas mudanças atingiram, de modo peculiar, a camada gerencial (gestores intermediários) localizada entre o topo (top managers) e a base (operação) da organização. Isto porque as organizações ao substituírem o modelo taylorista-fordista que até então orientava as suas estruturas operacionais e de gestão, passaram a adotar sistemas mais flexíveis e adaptáveis. Embora essa migração tenha ocorrido como alternativa para se lidar com as instáveis condições do ambiente político-econômico, ela fez com que os gestores intermediários tivessem de encontrar novas formas de pensar e realizar o seu fazer, diante das mutações que afligiram, decisivamente, a configuração do mundo organizacional e do trabalho contemporâneo.

Essas mudanças impactaram as camadas gerenciais em diversas regiões e países (ver, por exemplo: AlHAKIM; HASSAN, 2011; BUSS; KUYVENHOFEN, 2011; HALLIER, 2004; OUIMET, 2003). Mas quando o foco passa a ser a especificidade deste contexto no
Brasil, observa-se que os gestores intermediários foram responsáveis pela formação da classe média no Brasil desde o inicio da industrialização do país (BRESSERPEREIRA, 1962; AZEVEDO; TONELLI; SILVA, 2015). Esta característica faz com que a perda do trabalho represente, para essa camada gerencial, uma grande ameaça ao modo de vida deste grupo, pois manter-se na posição significa dar continuidade a uma condição econômica e social privilegiada num país de profundas desigualdades sociais.

Com este panorama como pano de fundo este artigo tem por objetivo discutir as estratégias de sobrevivência usadas pelo grupo de gestores intermediários no contexto das organizações brasileiras. Para tanto, foram entrevistados em profundidade 15 gestores intermediários em três grandes empresas instaladas na região da Grande São Paulo, sendo estas: uma multinacional americana de alta tecnologia; uma empresa multinacional brasileira na área petroquímica; e uma empresa brasileira de telecomunicação, joint venture de capital espanhol, português e brasileiro.

Após esta introdução o artigo segue organizado da seguinte forma: a próxima seção apresenta alguns trabalhos que trazem discussões sobre o papel dos gestores intermediários nas empresas e suas vulnerabilidades; em seguida indicamos o escopo metodológico do estudo, no qual detalhamos informações sobre as empresas e os gestores entrevistados; posteriormente são discutidos os resultados obtidos na pesquisa; por fim, realizamos as conclusões do estudo, reconhecemos os limites do trabalho e incentivamos futuras pesquisas.

\section{Gestores Intermediários e suas Vulnerabilidades}

Quando Taylor (1912) desenvolveu a teoria da administração científica, ele tinha a crença de que a emergência da camada gerencial era crucial para o sucesso organizacional. E em boa medida, o século $\mathrm{XX}$ viu o surgimento da gerência como profissão por direito próprio, uma vez que os gerentes passaram a serem entendidos como um grupo cujo objetivo é assegurar que a organização se adapte de maneira controlada ao ambiente mutante, para que assim, consiga servir àquelas pessoas que têm controle sobre ela (LORSCH et al., 1978).

Inseridos nesse grupo estão os middles managers que 
têm sido identificados como uma gerência geral que é responsável por uma unidade de negócios em um nível hierárquico intermediário (UYTERHOEVEN, 1972); uma autoridade hierárquica entre a operação e o topo (MINTZBERG, 1989); e/ou aqueles abaixo de um pequeno grupo de gerentes de alto escalão e acima do primeiro nível de supervisão (DOPSON; NEUMAN, 1996). Na literatura de gerenciamento, os gestores intermediários têm o papel particular de articular questões relacionadas ao conjunto de terceiros, fornecedores e prestadores de serviços que gravitam em torno da organização para qual o gestor intermediário realiza o seu trabalho (WILLCOCKS; GRIFFITHS, 2010). Sobretudo, articulam os interesses mais estratégicos da alta gerência e os trabalhadores e gestores da linha de frente da organização (PINSONNEAULT; KRAEMER, 1997; RAES et al., 2011). Ou seja, esse grupo de gestores concentra a informação para os níveis superiores e focaliza as ações para os níveis inferiores (FLOYD; WOOLDRIDGE, 1997; CONWAY; MONKS, 2011). Este fato evidencia que os gestores intermediários possuem e exercem certo poder em relação às possibilidades de se moldar o contexto organizacional, se lhes convier, segundo seus interesses particulares.

É no exercício deste poder que os middle managers formam uma espécie de nó organizacional, em face das redes de relacionamento estabelecidas pelos gestores intermediários nos exercícios de suas profissões. Essas redes emergem de relações formais e informais oriundas de trocas de informação e influência as quais, por sua vez, são estabelecidas entre os gestores quando no exercício de seus papéis de liderança. A influência exercida por essas redes decorre da concentração que realizam do capital intelectual, dos recursos humanos e materiais, pois é deste conjunto de elementos que emerge o impacto de tais redes nas organizações (FLOYD; WOOLDRIDGE, 1997; CONWAY; MONKS, 2011).

Gestores intermediários representam, portanto, a média-gerência responsável por realizar a ligação entre a alta gerência e o nível operacional da organização, tanto do ponto de vista técnico quanto de conhecimento, e desempenham papel fundamental na redução e ou absorção das incertezas decorrentes dos eventos não antecipados pela organização (DOPSON; NEUMANN, 1998; BUSS; KUYVNHOFEN, 2011). Também são os responsáveis pela implantação das estratégias elaboradas pela alta gerência, pela comunicação da visão corporativa em um nível prático para o pessoal envolvido em sua operação (LAVARDA; CANET-GINER; PERIS-BONET, 2010). Entretanto, qualquer que seja sua definição, os gestores intermediários representam despesas gerais ou adicionais para a operação de qualquer organização e, desta forma, necessitam justificar sua existência "adicionando valor", ou seja, criando benefícios que excedam os custos que representam (CLEGG; MCAULEY, 2005).

\section{Visões Teóricas sobre os Gestores Intermediários}

Clegg e McAuley (2005) indicam que na teoria da administração existem quatro discursos dominantes a respeito dos gestores intermediários. O primeiro destes discursos - situado no início dos anos de 1970 - os apresenta como representantes dos valores centrais da organização e que através desta orientação de valores os gestores intermediários se tornariam agentes do controle organizacional. Neste sentido, eles são a ponte de transposição do paradoxo entre a necessidade de mudar para atingir a visão de futuro e a manutenção do estado atual que mantém a organização funcionando, evitando sua desestabilização e o surgimento de crises durante a transição (JANCZAK, 2004; HOLE, 2010).

O segundo discurso emergiu ao final dos anos de 1970, mas se tornou particularmente poderoso no início dos 1980, representando os gestores intermediários como essencialmente agentes de controle centrados em seus próprios interesses. Neste discurso, os gestores intermediários são essencialmente redundantes, uma camada de ruído entre a visão e estratégias dos top managers e os empregados.

Já o terceiro discurso, que se tornou cada vez mais influente em meados da década de 1980, apresenta os gestores intermediários como atores-chave no desenvolvimento do discurso gerencial. Aqui, os middle managers são vistos como um agente de controle da burocracia corporativa e, portanto, são vistos como agentes dos top managers. Neste sentido, tanto Floyd e Wooldridge (1997) como Kanter (2004) enfatizam o papel dos gestores intermediários está em decidir realizar ou não ações do tipo: flexibilizar as regras e políticas vigentes em prol da consolidação de novos projetos; prover recursos para novos empreendimentos; encorajar discussões; e compartilhar informações dentro da organização. 
Em suma, a gerência intermediária constitui um grupo de centralização de poder quanto aos processos de tomada de decisão (PETERSON, 1995; AZEVEDO; TONELLI; SILVA, 2015). Assim, a questão de alinhamento entre os gestores intermediários e seus superiores, consiste no esforço desses gestores em conseguirem manter seus status, influências e reputações, pois esses profissionais tendem a subordinar os problemas que seus funcionários enfrentam em prol de seus próprios interesses, isto é, a favor do atendimento das expectativas de seus superiores e de suas agendas pessoais (HALLIER, 2004; DUARTE; SILVA, 2013).

Por fim, o quarto discurso, que também emergiu na década de 1980 com elementos da primeira visão da década de 1970, visualiza os gestores intermediários como transmissores dos valores estratégicos centrais no papel de mentor e guia. Nesta visão, a gestão intermediária está comprometida com aqueles que guardam o conhecimento organizacional, numa versão de um controle "benigno" da memória organizacional. Ou seja, os middles managers representam um elo vital entre os formuladores da visão e os seus seguidores e têm o potencial de vencer a inércia organizacional, ao manejar os símbolos, valores e crenças da organização em prol de um plano de ação (VALENTINO, 2004; DUARTE; SILVA, 2013).

\section{Poder dos Middle Managers nas Mudanças Organizacionais}

Para Pinsonneault e Kraemer (1997) a mais comum das organizações é a hierárquica, que pode ser centralizada ou descentralizada. Quando o controle de decisão é centralizado, os top managers têm grande influência e seus interesses serão melhor atendidos. Por outro lado, quando o controle é descentralizado, os gestores intermediários terão grande influência e seus interesses serão atendidos; quando a estrutura de decisão é centralizada, seu papel é mais rotineiro, estruturado e primariamente construído para gerar informação. Em tais casos, terão menor poder de influência. Mas quando a estrutura de decisão é descentralizada, o papel dos gestores intermediários é em grande parte desestruturado e parte de seu trabalho pode ser computadorizado, fazendo com que, neste contexto, seu poder de influência seja maior.

Floyd e Wooldridge (1997) entendem a organização como uma rede de relacionamentos onde os gestores intermediários são os nós de interligação entre os top managers e os executores em sua linha de frente. Por esse motivo, haverá nós mais densos que outros, isto é, haverá gestores intermediários que acumulam mais poder de influência do que outros, como discutido anteriormente, e esta troca de influências distorcerá a rede. Não por acaso, um dos maiores desafios do gestor intermediário é a estruturação de seu próprio papel e o consequente repensar sobre a maneira como irá desenvolver seu trabalho diante o cenário organizacional de mudanças que é, per si, cheio de signos, sinais e comportamentos que atribuem significados aos processos de mudança (BALOGUN, 2003).

Mas o quê os middle managers podem realmente mudar nas organizações? Há o entendimento de que existem, basicamente, cinco categorias em que eles podem atuar: na estrutura, na cultura, na tecnologia, no ambiente e nas pessoas (OUIMET, 2003). Mudar a estrutura implica fazer uma alteração nas relações de autoridade, nos mecanismos de coordenação, no redesenho de cargos ou como as tarefas são formalmente divididas, agrupadas e coordenadas (WOOD JR, 2004). Os gerentes podem considerar também o redesenho dos cargos ou da programação de trabalho; os cargos podem ser redefinidos ou enriquecidos, ou podem ser introduzidos horários flexíveis de trabalho (DRUCKER, 1988; MILLS, 1991; AZEVEDO; TONELLI; SILVA, 2015).

Mudar a cultura exige a reformulação dos valores centrais da organização. Talvez seja muito mais fácil mudar a estrutura de uma organização do que mudar a sua cultura, pois esta tende a ser muito resistente à mudança (OUIMET, 2003). Mas isto não quer dizer que a cultura não possa ser mudada (VALENTINO, 2004). As potencialidades para essa possibilidade de mudança provem das condições geradas por circunstâncias atípicas oriundas, por exemplo, de situações como: uma grave crise; uma nova liderança na direção da empresa; uma organização muito pequena; e uma organização com uma cultura enfraquecida e, portanto, susceptível aos direcionamentos estratégicos assumidos pela camada gerencial.

Em relação à mudança da tecnologia, esta categoria envolve modificações no modo como o trabalho, em si, é processado e na forma como os métodos e equipamentos utilizados nesse processo, são igualmente alterados. Mas a introdução de um novo aparato tecnológico nas organizações, em muito, está relacionado aos fatores competitivos ou inovadores 
que emergem dentro do setor em que atua a organização (LASSEN; WAEHRENS; BOER, 2009).

Já as mudanças referentes ao ambiente se atentam para os aspectos relacionados a alteração do espaço e da disposição do local do trabalho (OUIMET, 2003). Nesse sentido, quando os gestores intermediários vislumbram mudanças em relação ao ambiente, de modo geral, o foco está voltado para o detalhamento das demandas de trabalho e das exigências de interação formal entre os trabalhadores. Também abrange aspectos a configurações do desenho de interiores e localização de equipamentos, ou seja, do espaço físico - organizacional e de trabalho - em si.

Por fim, mudanças relativas à categoria pessoas (e, neste caso, mudar o comportamento dos funcionários), se dão geralmente através de processos de: mudança de atitudes, que são declarações de caráter avaliativo (favoráveis ou desfavoráveis) em relação a objetos, pessoas ou acontecimentos; aprendizagem, entendida como qualquer mudança relativamente permanente no comportamento, em decorrência da experiência; e, as ações em que os middle managers fixam expectativas elevadas para os seus funcionários, mas não tão elevadas a ponto de ser intimidantes ou inviáveis, iniciando assim um processo que pode levar à realização de suas expectativas (OUIMET, 2003).

\section{Jogos de Poder nas Organizações}

Como pudemos observar na discussão anterior, os gestores intermediários participam dos jogos de poder internos à dinâmica organizacional. O trabalho de Ouimet (2003) avança na analise aprofundada de tais jogos, também conhecidos como habilidades políticas, ao reconhecer que os jogos de poder são passíveis de serem traduzidos em duas estratégias básicas: estratégias de consolidação de poder e estratégias de proteção de posição.

A estratégia de consolidação engloba os jogos de poder utilizados pelos atores com pouco poder organizacional disponível, mas que, em um contexto de trabalho favorável a seu desenvolvimento, evoluem. Esses atores beneficiam-se, então, de um clima de trabalho positivo devido a variadas razões, sendo as principais: um chefe atencioso, colega de trabalhos honestos e bem-intencionados, relações de trabalho harmoniosas entre os empregados, um estresse organizacional equilibrado e uma situação financeira estimulante para a empresa. A utilização da estratégia de consolidação de poder permite a estes atores aumentar a importância de seus recursos e, consequentemente, ampliar as chances de subir nos escalões hierárquicos (OUIMET, 2003; AZEVEDO; TONELLI; SILVA, 2015).

Por outro lado, contrariamente à estratégia precedente, a estratégia de proteção de posição comporta jogos de poder utilizados pelos atores que possuem um fraco poder organizacional e trabalham em um clima negativo de trabalho. $\mathrm{Na}$ maior parte das vezes, as principais razões para tal clima são: chefes com personalidades difíceis; colegas de trabalho agressivos e, fundamentalmente, interessados no sucesso pessoal; uma cultura organizacional patogênica; um estresse organizacional intenso e não controlado; uma morosidade econômica no setor de atividade da empresa; e transformações de estrutura e das atividades da empresa. Ouimet (2003) comenta que o recurso à estratégia de proteção de posição visa assegurar a defesa dos atores desprovidos de recursos. Essa estratégia não permite, entretanto, o aumento de seu poder, pois o seu objetivo é limitar os estragos e preservar a posição organizacional do indivíduo que a utiliza.

O fato é que a liderança sênior (top managers) pode realizar uma mudança brusca, através da reorientação estratégica do negócio, enquanto os gestores intermediários podem fazer refinamentos (melhoria contínua) ou mudanças incrementais (PINSONNEAULT; KRAEMER, 1997; AZEVEDO; TONELLI; SILVA, 2015). É nessa direção que a estratégia de reorientação, também denominada de incremental, funciona modificando a estrutura, a tecnologia e finalmente o trabalho. Estas modificações impactam profundamente os gestores intermediários, já que a estrutura da rede e o papel desempenhado estão sendo alterados.

Dentro de uma organização sempre haverá uma coalizão dominante que pode ser composta de uma elite gerencial, elite tecnocrática ou um arranjo plural de atores, como top managers e gestores intermediários. Estas interações sociais entre as diversas camadas gerenciais de uma organização se transformam em fator crítico no processo de desenvolvimento de novas ideias e competências que influenciarão a estratégia da organização (PAPPAS, 2004; PAPPAS; WOOLDRIDGE， 2007; BISELLI; TONELLI; SILVA, 2015). 
Vimos que os gestores intermediários participam de jogos de poder e têm influência sobre os processos de mudanças organizacionais. Mas a literatura discutida anteriormente, não aponta como esses gestores constroem suas estratégias. Por esse motivo, o objetivo desta pesquisa é contribuir para o preenchimento desta lacuna, ao se propor investigar quais são as estratégias (de sobrevivência) utilizadas por esses gestores nos arranjos e nós organizacionais.

\section{Abordagem Metodológica}

Para discutir as estratégias de sobrevivência usadas pelo grupo de gestores intermediários no contexto empresarial brasileiro, optamos por um estudo qualitativo. Esta escolha metodológica aponta para aquilo que Bluhm et al. (2011) definem como sendo a natureza de pesquisa que se orienta para o entendimento da realidade pesquisada como dotada de significado, construída, local e específica, não tendo a pretensão de generalizar as descobertas de forma ampla, tal como se propõe o escopo deste trabalho.

Os resultados deste trabalho decorrem da entrevista em profundidade e posterior análise dos dados obtidos com 15 gestores intermediários de três grandes empresas instaladas no Brasil: uma multinacional americana de alta tecnologia, uma empresa multinacional brasileira na área petroquímica e uma empresa brasileira de telecomunicação, joint venture de capital espanhol, portuguesa ebrasileira. Os gestores intermediários destas organizações foram intencionalmente selecionados pela posição e responsabilidades que desempenhavam nestas empresas. Estas empresas foram escolhidas por representarem diferentes estruturas organizacionais, com diferentes culturas e histórias de crescimento. São empresas líderes em seus segmentos de mercado, muito distintos em suas características e concorrências. Este conjunto de fatores permitiu uma amostra mais plural de ambientes corporativos com suas oportunidades e ameaças aos gestores intermediários em sua busca de desenvolvimento.

Em relação aos detalhes mais específicos, a empresa multinacional norte-americana está presente em mais de 100 países, tem cerca de 70 anos de idade, seus fundadores já faleceram e está na quarta geração de topmanagers. Está no Brasil há cerca de 40 anos e opera no mercado de alta tecnologia de informação, caracterizado por ciclos de vida de lançamento de produtos cada vez menor e pressionada pela necessidade de se diferenciar da concorrência através de serviços agregados à entrega dos produtos, num mercado com forte direcionamento por preço. É uma empresa altamente estruturada, com cargos bem definidos, mas que passou recentemente por uma fusão complexa com uma empresa, também americana, de grande porte. Emprega cerca de 100.000 pessoas, sendo que deste total 2.000 atuam no Brasil.

A empresa brasileira de telecomunicação, joint-venture de capital espanhol, português e brasileiro, atravessou um período de formação conturbado e vive o desafio de se manter na liderança em seu segmento de mercado, cuja concorrência é cada vez mais feroz, obrigando-a a lançar produtos em ciclos cada vez mais curtos e a custos menores. Comparada à empresa americana é ainda não estruturada, cujos cargos podem assumir mais ou menos funções à medida das necessidades. Opera com cerca de 4.000 pessoas no Brasil. Por resultar de muitas consolidações e compras de outras companhias de telecomunicações desde o período da privatização do setor, esta empresa enfrenta, em paralelo, o desafio de se profissionalizar, para responder rapidamente ao mercado e se desvincular de uma cultura estatal.

Já a empresa brasileira de petroquímica opera em um mercado bastante estável, sem grande concorrência, mas, ainda assim, atua de modo bem agressivo em relação à aquisição de concorrentes. É uma empresa de origem e cultura familiar, cujos fundadores ainda são vivos e administram a empresa a mais de 50 anos. Em seu histórico de crescimento há a aquisição de empresas estatais brasileiras. Opera com cerca de 4.000 pessoas no Brasil e é altamente alavancada com serviços de terceiros. Esta organização é o resultado de um acordo com grandes companhias de construção brasileiras, o que constituiu uma joint-venture.

Em relação à coleta de dados, foram realizadas entrevistas semiestruturadas com base no seguinte roteiro: a) perfil do profissional e de seus conteúdos; b) histórico do desenvolvimento de sua carreira na empresa; c) abrangência de sua influência sobre a organização; d) rede de relacionamentos em 360 graus, isto é, com seus superiores, pares e subordinados; e) conjunto de valores e crenças no tocante ao que é ou não é importante para o desenvolvimento de sua carreira; f) identificação de padrões de comportamento que evidenciassem estratégias para sobrevivência e ou crescimento dentro de suas organizações; g) e consideração sobre questão de gênero, como restringindo ou não as estratégias. 
As entrevistas foram gravadas para posterior transcrição. Em posse das entrevistas transcritas foi possível executar o processo de análise das entrevistas por meio de uma perspectiva interpretativa pragmática (MERRIAM, 2002). Por esse processo de análise foram identificadas as estratégias implantadas pelos gestores intermediários, bem como inúmeros aspectos relacionados ao tipo de estratégia utilizada, as políticas de trabalho da companhia, o estágio de amadurecimento da organização; e a influência que o gênero provoca nas estratégias. Os detalhes desses resultados são apresentados a seguir.

\section{Apresentação e Discussão dos Resultados}

A seguir, serão apresentados os resultados obtidos a partir da análise das entrevistas, de acordo com cada empresa pesquisada. Consideramos que há especificidades para os gestores intermediários, de acordo com a empresa (e sua cultura/organização) em que trabalham. Ao final, é apresentada uma síntese que contempla estratégias de sobrevivência utilizadas por todos os entrevistados.

Primeiramente, na empresa multinacional brasileira, foi possível encontrar traços fortes de paternalismo. Foi comentado por um dos entrevistados que alguns colegas - também gestores intermediários - ao saírem da companhia não conseguiram se reempregar, pois o baixo incentivo dado pela empresa a desenvolverem seus conhecimentos havia levado-os a diminuir o grau de sua empregabilidade e que isto amedrontava aqueles que ficaram na organização, tornando-os mais submissos a certas condições impostas pela empresa. Em relação às principais estratégias utilizadas pelos gestores intermediários, o quadro 01 apresenta a síntese dos resultados obtidos na empresa brasileira.

Quadro 01 . Resumo do conjunto de entrevistas na multinacional brasileira

\begin{tabular}{|c|c|}
\hline \multicolumn{2}{|c|}{ Empresa multinacional brasileira } \\
\hline Resumo dos gestores entrevistados & Principais estratégias empregadas \\
\hline $\begin{array}{l}45 \text { anos (homem) } \\
\text { Gerente de Planejamento } \\
\text { Equipe com } 7 \text { funcionários }\end{array}$ & $\begin{array}{l}\text { Alinhamento com a chefia } \\
\text { Busca de desafios } \\
\text { Criação e fortalecimento de networking com pares, superiores e } \\
\text { equipe } \\
\text { Capacitação em conteúdos }\end{array}$ \\
\hline $\begin{array}{l}44 \text { anos (homem) } \\
\text { Gerente de Operações e Serviços em TI } \\
\text { Equipe com } 165 \text { funcionários }\end{array}$ & $\begin{array}{l}\text { Alinhamento com a chefia } \\
\text { Busca de desafios } \\
\text { Criação e fortalecimento de networking com pares, superiores e } \\
\text { equipe } \\
\text { Capacitação em conteúdos }\end{array}$ \\
\hline $\begin{array}{l}33 \text { anos (mulher) } \\
\text { Gerente de Sistemas } \\
\text { Equipe com } 10 \text { funcionários }\end{array}$ & $\begin{array}{l}\text { Alinhamento com a chefia } \\
\text { Criação e fortalecimento do networking com superiores } \\
\text { Capacitação em conteúdos }\end{array}$ \\
\hline $\begin{array}{l}30 \text { anos (mulher) } \\
\text { Gerente de TI } \\
\text { Equipe com } 8 \text { funcionários }\end{array}$ & $\begin{array}{l}\text { Alinhamento com a chefia } \\
\text { Criação e fortalecimento do networking com superiores } \\
\text { Busca de desafios }\end{array}$ \\
\hline $\begin{array}{l}31 \text { anos (homem) } \\
\text { Gerente de Divisão de Planejamento e Parcerias } \\
\text { Equipe com } 4 \text { funcionários }\end{array}$ & $\begin{array}{l}\text { Alinhamento com a chefia } \\
\text { Capacitação em conteúdos }\end{array}$ \\
\hline
\end{tabular}

Fonte: dados da pesquisa 
A empresa de capital misto luso-espanhol-brasileiro mantém uma cultura que exige alta flexibilidade, disponibilidade e adaptabilidade de seus gestores intermediários. Dentro deste ambiente cultural e pouco estruturado, as entrevistas sugerem que: profissionais orientados a resultados levam grande vantagem em relação a colegas que sejam processuais; profissionais generalistas aproveitaram as melhores oportunidades que surgem na organização; os profissionais especialistas tornaram-se subalternos na organização. Em relação às principais estratégias utilizadas pelos gestores intermediários, o quadro 02 apresenta a síntese dos resultados obtidos na empresa de capital misto luso-espanhol-brasileiro.

Quadro 2 . Resumo das entrevistas dos gestores intermediários da empresa Luso-Espanhola-Brasileira de Telecom

\begin{tabular}{|c|c|}
\hline \multicolumn{2}{|c|}{ Empresa luso-espanhola-brasileira de Telecom } \\
\hline Resumo dos gestores entrevistados & Principais estratégias empregadas \\
\hline $\begin{array}{l}29 \text { anos (homem) } \\
\text { Gerente de Divisão de Marketing Corporativo } \\
\text { Equipe com } 45 \text { funcionários }\end{array}$ & $\begin{array}{l}\text { Alinhamento com a chefia } \\
\text { Busca de desafios } \\
\text { Criação e fortalecimento do networking com pares, superiores e } \\
\text { equipe } \\
\text { Capacitação em conteúdos } \\
\text { Utilização da posição estratégica da gerência que ocupa para } \\
\text { evolução }\end{array}$ \\
\hline $\begin{array}{l}32 \text { anos (mulher) } \\
\text { Gerente de Estratégia Corporativa } \\
\text { Equipe com } 11 \text { funcionários }\end{array}$ & $\begin{array}{l}\text { Alinhamento com chefia } \\
\text { Busca de desafios } \\
\text { Capacitação em conteúdos } \\
\text { Criação e fortalecimento do networking com pares, superiores e } \\
\text { equipe }\end{array}$ \\
\hline $\begin{array}{l}31 \text { anos (homem) } \\
\text { Gerente de Planejamento Estratégico Corporativo } \\
\text { Equipe com } 7 \text { funcionários }\end{array}$ & $\begin{array}{l}\text { Alinhamento com chefia } \\
\text { Busca de desafios } \\
\text { Criação e fortalecimento do networking com pares, superiores e } \\
\text { equipe } \\
\text { Capacitação em conteúdos } \\
\text { Utilização da posição estratégica da gerência que ocupa para } \\
\text { evolução }\end{array}$ \\
\hline $\begin{array}{l}33 \text { anos (mulher) } \\
\text { Gerente de Controle e Auditoria } \\
\text { Equipe com } 6 \text { funcionários }\end{array}$ & $\begin{array}{l}\text { Alinhamento com a chefia } \\
\text { Busca de desafios } \\
\text { Criação e fortalecimento do networking com pares, superiores e } \\
\text { equipe } \\
\text { Capacitação em conteúdos } \\
\text { Adaptabilidade } \\
\text { Utilização da posição estratégica da gerência que ocupa para } \\
\text { evolução }\end{array}$ \\
\hline $\begin{array}{l}33 \text { anos (homem) } \\
\text { Gerente de Marketing para Pequenas e Médias } \\
\text { Empresas } \\
\text { Equipe com } 17 \text { funcionários }\end{array}$ & $\begin{array}{l}\text { Alinhamento com a chefia } \\
\text { Busca de desafios } \\
\text { Criação e fortalecimento do networking com pares, superiores e } \\
\text { equipe } \\
\text { Capacitação em conteúdos }\end{array}$ \\
\hline
\end{tabular}

Fonte: dados da pesquisa 
A cultura da companhia americana incentiva o trabalho fora do escritório e muitos funcionários optam pelo trabalho em casa, conhecido nesta empresa como home office. Este incentivo se dá pelo pagamento, por parte da empresa, das despesas de conectividade de alta velocidade entre o notebook e seus equipamentos periféricos como web câmeras, digitalizadores de documentos e impressoras - também fornecidas por ela - e o escritório. Outros incentivos relacionados a esta prática são a disponibilização de espaços menores, mesas e poltronas nos escritórios - que inviabiliza o trabalho de todos ao mesmo tempo no escritório - e a utilização intensiva deste recurso tecnológico por parte da alta gerência. Em relação às principais estratégias utilizadas pelos gestores intermediários, o quadro 03 apresenta a síntese dos resultados obtidos na companhia americana.

Quadro 3 . Resumo das entrevistas dos gestores intermediários da empresa norte-americana de alta tecnologia

\begin{tabular}{|c|c|}
\hline \multicolumn{2}{|c|}{ Empresa norte-americana de alta tecnologia } \\
\hline Resumo dos gestores entrevistados & Principais estratégias empregadas \\
\hline $\begin{array}{l}45 \text { anos (mulher) } \\
\text { Gerente de Operações para América Latina } \\
\text { Equipe com } 30 \text { funcionários }\end{array}$ & $\begin{array}{l}\text { Alinhamento com a chefia } \\
\text { Mapeamento e análise das agendas dos gerentes e diretores } \\
\text { Criação e fortalecimento do networking com pares, superiores e } \\
\text { equipe } \\
\text { Declaração explícita do objetivo de carreira } \\
\text { Preparação de sucessores } \\
\text { Utilização da posição estratégica da gerência que ocupa para } \\
\text { evolução } \\
\text { Capacitação em conteúdos } \\
\text { Adaptabilidade }\end{array}$ \\
\hline $\begin{array}{l}39 \text { anos (homem) } \\
\text { Gerente de Negócio de Consultoria no Brasil } \\
\text { Equipe com } 150 \text { funcionários }\end{array}$ & $\begin{array}{l}\text { Alinhamento com a chefia } \\
\text { Declaração explícita do objetivo de carreira } \\
\text { Criação e fortalecimento do networking com pares, superiores e } \\
\text { equipe } \\
\text { Utilização das regras internas para crescimento na carreira } \\
\text { Preparação de sucessores } \\
\text { Adaptabilidade }\end{array}$ \\
\hline $\begin{array}{l}40 \text { anos (homem) } \\
\text { Gerente da área de consumo para small business e } \\
\text { bome para o Brasil } \\
\text { Equipe com } 17 \text { funcionários }\end{array}$ & $\begin{array}{l}\text { Alinhamento com a chefia } \\
\text { Criação e fortalecimento do networking com pares, superiores e } \\
\text { equipe } \\
\text { Utilização das regras internas para crescimento na carreira } \\
\text { Preparação de sucessores }\end{array}$ \\
\hline $\begin{array}{l}39 \text { anos (mulher) } \\
\text { Gerente da prática de gestão de TI para o Brasil } \\
\text { Equipe com } 17 \text { funcionários }\end{array}$ & $\begin{array}{l}\text { Alinhamento com a chefia } \\
\text { Criação e fortalecimento do networking com pares, superiores e } \\
\text { equipe } \\
\text { Utilização das regras internas para crescimento na carreira } \\
\text { Capacitação em conteúdos } \\
\text { Adaptabilidade }\end{array}$ \\
\hline $\begin{array}{l}35 \text { anos (homem) } \\
\text { Gerente da prática de manufatura para América } \\
\text { Latina } \\
\text { Equipe com } 10 \text { funcionários }\end{array}$ & $\begin{array}{l}\text { Alinhamento com a chefia } \\
\text { Utilização das regras internas para crescimento na carreira } \\
\text { Capacitação em conteúdos } \\
\text { Adaptabilidade }\end{array}$ \\
\hline
\end{tabular}

Fonte: dados da pesquisa 
Considerando os resultados obtidos, apresenta-se a seguir uma síntese com as estratégias mais comuns utilizadas pelos entrevistados:

1. Ser percebido pelos pares, funcionários e superiores como detentor do conhecimento do conteúdo técnico para desempenhar o papel gerencial, justificando, portanto, a posição no cargo.

2. Buscar desafios junto aos superiores, significando com isto "roubar" trabalho de outros pares concorrentes e enriquecer as responsabilidades e abrangência do cargo, criando o potencial de crescimento.

3. Alinhamento com os superiores, significando complementar, potencializar, ampliar o grau de abrangência das responsabilidades do superior e com isto acompanhar a estratégia de trabalho do superior.

4. Adaptação às mudanças, significando com isto se fixar nos resultados e não se prender ao status quo vigente (chefias, valores, crenças, organização atual).

5. Criação e fortalecimento da rede de relacionamentos colaborativa com os pares e com os funcionários, significando com isto realizar este trabalho através dos funcionários, realizar trocas com os pares, criar coalizões com objetivos mútuos com os pares e eventualmente com os superiores.

6. Utilização da posição estratégica ocupada para fortalecer seu relacionamento com o superior, significando criar uma rede dentro da organização, orientada a prover ao superior os meios que lhe reforcem esta estratégia.

7. Preparação de sucessores para que possa ter flexibilidade e rapidez na realização de movimentos estratégicos dentro da organização.

8. Conhecimento profundo sobre as regras, políticas, valores e crenças estabelecidos e se valer destas para realizar seus movimentos.
9. Identificação das agendas e objetivos dos superiores e dos superiores de seus superiores para antecipação de movimentos corporativos para tomada de ações antes dos pares.

10. Declaração explícita de objetivos de crescimento com o superior e busca de seu comprometimento e facilitação para alcançálos.

As cinco primeiras estratégias foram identificadas como as comumente realizadas pela grande maioria dos gestores intermediários entrevistados. Poderíamos descrevê-las como as estratégias básicas do gestor intermediário para crescimento, manutenção ou sobrevivência na posição. Esse resultado condiz com o argumento defendido por Floyd e Wooldridge (1997) e Conway e Monks (2011), sobre a centralidade do desenvolvimento de redes de contatos e proximidade dos superiores, enquanto estratégias para manutenção e sobrevivência na posição gerencial, bem como sendo esse um caminho para exercer e demonstrar a sua capacidade propositiva de trabalho. Estas estratégias ficam mais evidentes na empresa de Telecom, com capital luso-espanhol-brasileiro devido a sua baixa estruturação de cargos e a necessidade de maior flexibilidade e adaptação a um mercado muito dinâmico. Este resultado reforça o argumento de Azevedo, Tonelli e Silva (2015), sobre a flexibilidade percebida, enquanto estratégia contínua, em camadas do nível gerencial. No entanto, tal resultado contrasta com as afirmações de Peterson (1995) e Raes et al. (2011), sobre o fato dos gestores intermediários centralizarem o poder no processo de tomada de decisão nas organizações, o que contrasta com o resultado percebido, neste artigo, sobre a flexibilidade enquanto uma prática e enquanto um valor para os gestores intermediários. $\mathrm{Na}$ empresa multinacional brasileira nota-se que a maioria dos gestores intermediários, pelo menor tempo na empresa, ainda estão desenvolvendo estratégias para se consolidarem na posição, o que vai ao encontro dos argumentos de Hallier (2004) e Duarte e Silva (2013) sobre a relação entre tempo e carreira, enquanto um mecanismo central que legitima os gestores para tomadas de decisões mais amplas nas organizações.

A estratégia de número quatro está relacionada a situações mutantes onde vínculos fortes, entre o gestor intermediário e seu superior, são vistos como 
uma desvantagem no caso da substituição de seu superior. Também foi observado que as estratégias $1 \mathrm{e}$ 3 são básicas de reconhecimento pelos entrevistados. De acordo com um deles: "você não se mantém vivo sem isto". Observou-se que a estratégia cinco pode ser utilizada quando o gestor intermediário já tem consolidada sua posição e começa a olhar além para futuros movimentos.

Já as estratégias 6 a 10 são estratégias mais sofisticadas e foram utilizadas por gestores intermediários com mais tempo na empresa, que se utilizaram, portanto, da vantagem competitiva de maior conhecimento da estrutura, do relacionamento mais profundo com superiores e de acordos anteriormente já estabelecidos. Estas estratégias ficam mais evidentes na empresa multinacional norte-americana pela sua forte estruturação de cargos e previsibilidade que dá aos resultados das avaliações de desempenho. De acordo com as entrevistas essas estratégias são muito sofisticadas, pois subentendem um vínculo de relacionamento estreito entre o gestor intermediário e seu superior, e que são utilizadas somente quando se tornam amigos e confidentes, relacionadas ao grande tempo de trabalho na empresa ou a profundidade da amizade entre eles. Esse resultado endossa a afirmação de Conway e Monks (2011) sobre a centralidade das redes pessoais de contato, estabelecidas e buscas pelos gestores intermediários junto aos seus superiores, a afim de consolidar privilégios e melhores perspectivas para o avanço em suas carreiras profissionais.

Os resultados obtidos, nesta pesquisa, também indicam que há um reforço positivo entre idade da empresa, seu grau de estruturação formal de políticas administrativas, cargos e salários com estratégias explícitas empreendidas pelos gestores intermediários. Por exemplo, na empresa norte-americana, todos os gestores intermediários utilizaram conscientemente o processo de avaliação de carreira para negociar com seu superior novas posições e, dentre eles, observou-se que os que tinham mais tempo de casa desenvolveram estratégias sofisticadas quanto à sua carreira: uma das gestoras explicitamente informou que estes momentos eram usados para sincronização do momento de sua subida com o de sua chefia bem como os dois momentos de "parada" quando pôde engravidar e manter-se em sua cidade durante os primeiros meses de amamentação de seus filhos. Outro entrevistado informou que desenvolveu com seu superior um plano de ocupação de novos postos gerenciais para os próximos anos. Estes alinhamentos de longo prazo sugerem a criação de fortes vínculos entre os gestores intermediários dentro de uma hierarquia e podem ser vistos como "barreira de entrada" para outros competidores.

$\mathrm{Na}$ empresa luso-espanhola-brasileira não foram citadas estratégias que se valessem das regras e sim aquelas relacionadas com, como citou um dos gestores intermediários, "roubar o trabalho disponível para aumentar meu grau de exposição e visibilidade". Observou-se também que esta empresa mantém uma cultura que exige alta flexibilidade, disponibilidade e adaptabilidade de seus gestores intermediários. Dentro deste ambiente cultural e pouco estruturado, as entrevistas sugerem que profissionais orientados a resultados levam grande vantagem em relação a colegas que sejam processuais e que generalistas aproveitaram as melhores oportunidades que apareceram e que os especialistas se tornaram seus subalternos. Este resultado favorece a reprodução da afirmação feita por Pinsonneault e Kraemer (1997), Raes et al. (2011), e Monks (2011), sobre como a capacidade dos gestores intermediários em articular interesse mais estratégicos com a sua operacionalização pelos subordinados, favorece a valorização dos postos de gestão intermediária junto a cúpula estratégica e operacional das organizações. Por sua vez, isto promove o que Hallier (2004) e Duarte e Silva (2013) chamam de alinhamento entre gestores, superiores e operários.

A empresa norte-americana que oferece a modalidade de home-office para a realização das atividades de trabalho dos middle managers, deu condições para que as gestoras intermediárias pudessem cuidar de seus filhos, enquanto trabalhavam em casa, reduzindo assim o impacto de querer ser mãe e ao mesmo tempo desenvolverem suas carreiras. Neste caso, esta prática foi incentivada pela empresa e é culturalmente conhecida como work-life balance. Embora seja essa uma prática que pode agregar benefícios para o exercício do trabalho das gestoras intermediárias, o mesmo não se viu nas outras empresas, onde as gestoras intermediárias optaram por não casar ou não ter filhos para aumentar sua disponibilidade ao trabalho e poderem prosperar na empresa. Uma destas inclusive comentou na entrevista que "tinha ido além de suas expectativas e de sua família quanto ao seu desenvolvimento profissional". Em outra entrevista um dos gestores intermediários comentou que para se desenvolver profissionalmente tomou a decisão de se mudar de cidade e sua esposa o acompanhou 
no processo. Não se evidenciou o inverso, quando os entrevistados eram mulheres.

Além disso, observou-se que no processo de desenvolvimento na carreira algumas estratégias implícitas utilizadas com frequência pelos middle managers: tão importante quanto à criação de redes de relacionamento dentro da empresa são aquelas desenvolvidas pelo(a) profissional fora da empresa. Em uma situação um gestor intermediário realizou uma mudança de empresa e, depois de estabelecido, trouxe duas colegas para serem suas gerentes. Este movimento foi justificado por ele como necessário para estabelecer uma rede de sua confiança, o que também reforça o argumento já asseverado por Floyd e Wooldridge (1997) e Conway e Monks (2011), sobre a existência de redes pessoais de contatos, enquanto estratégia dos gestores intermediários. Em outra entrevista outro gestor intermediário foi convidado para ocupar um posto gerencial em outra empresa justamente para suportar, em um segundo momento, o movimento para cima do colega que o contratou. Com isto ele também rapidamente foi promovido para um posto gerencial. Em outra entrevista um gestor intermediário estima que $70 \%$ dos postos gerenciais são ocupados por indicação. Tais práticas sugerem ao menos três estratégias implícitas: fortalecimento da posição mais elevada por meio da construção de grupos subalternos altamente alinhados e confiáveis cujos elementos vieram de fora da empresa; utilização das posições como "moeda de troca" e que leva ao fortalecimento do relacionamento entre os gestores intermediários fora da empresa; e a manutenção de referências que possam fortalecer e dar credibilidade ao gestor intermediário quando este estiver competindo com outros candidatos por uma determinada posição.

\section{Conclusões}

Esta pesquisa qualitativa, teórico-empírica, foi desenvolvida à luz do seguinte objetivo: discutir as estratégias de sobrevivências usadas por gestores intermediários em contexto organizacional. Para que este objetivo foi atingido, procuramos sistematizar um referencial teórico-empírico acerca dos temas: gestores intermediários e suas vulnerabilidades; visões teóricas sobre gestores intermediários; poder dos middle managers nas mudanças organizacionais; e, jogos de poder nas organizações. Além disso, como base empírica de dados, conduzimos quinze entrevistas em profundidade com gestores intermediários atuantes em uma multinacional brasileira; uma empresa de capital misto luso-espanhou-brasileiro; e uma multinacional norte-americana. Todo esse processo nos deu condições para que atingíssemos o objetivo de pesquisa e, assim, chegássemos à algumas conclusões, as quais são articuladas a seguir.

\section{Contribuição para a Teoria}

Acreditamos que este trabalho oferece uma contribuição principal para a teoria. Enquanto outras pesquisas sobre gestores intermediários focam seus esforços de pesquisas no debate sobre a centralidade dos gestores intermediários na operacionalização da dinâmica organizacional, neste artigo, debatemos o tema focados na figura desses gestores, enquanto trabalhadores que se, por um lado, exercem poder dentro da dinâmica organizacional, por outro sofrem impactos nos modos como pensam e realizam o seu fazer. Nesse sentido, este artigo avança no debate sobre gestores intermediários no Brasil ao apresentar algumas das estratégias de poder mobilizadas por esses trabalhadores para sobreviverem ao contexto organizacional brasileiro.

A partir da interface entre referencial teórico-empírico e as entrevistas coletadas junto a quinze gestores intermediários, observou-se que desse conjunto de entrevistas emergiram dez estratégias de poder/ sobrevivência, a saber: ser percebido pelos pares como detentor de conhecimento; buscar desafios juntos aos superiores; ampliar o grau de abrangência junto aos superiores; adaptação as mudanças; criar redes de contato externas; fortalecer rede de interlocução com o superior; preparar sucessores visando maior flexibilidade; conhecer profundamente as regras e políticas da organização; identificar objetivos pretendidos pelos superiores; declarar explicitamente os objetivos pessoais de crescimento ao superior. Tais estratégias emergiram à medida que os gestores intermediários expuseram suas preocupações, valores, crenças e experiências, o revelou alguns de seus padrões de comportamento comuns e adaptações quase que darwinianas - ao momento dos negócios, ao nível de maturidade da corporação, e às pressões que esta impõe ao profissional gestor intermediário.

As estratégias de poder/sobrevivência manifestadas pelos gestores intermediários, emergiram em resposta às pressões ambientais ligadas ao seu tempo dentro 
da organização e, portanto, à profundidade dos relacionamentos estabelecidos no ambiente de trabalho e a sua própria posição dentro da hierarquia corporativa. Soma-se a isso, a rede de relacionamentos estabelecida fora da empresa, enquanto um mecanismo de proteção às pressões e mudanças organizacionais. De modo geral, as respostas revelaram que todos os gestores intermediários entrevistados desejam prosperar - em maior ou menor grau - e que nenhum deles queriam ser rotulados como fracassado, pois a perda da sua reputação representa o maior revés que a imagem de um gestor intermediários pode sofrer, vez que, aos olhos do mercado, pode sinalizar o fim de uma carreira promissora. Não por acaso, ficou patente que os gestores intermediários dão grande peso ao que o mercado e os seus pares percebem de sua competência e que a perda da reputação representará a imposição penosa de criação de uma nova rede de relacionamentos, de um reinício a partir do "zero". Isto representa um custo financeiro e psicológico que poucos podem suportar.

\section{Contribuições para a Prática}

Acreditamos que este trabalho oferece uma contribuição principal para a prática. Por meio desta pesquisa, concluí-se que o trabalho dos gestores intermediários permite a redução dos custos de controle e torna mais transparentes e críveis os seus indicadores ou métricas gerenciais. Ao nosso entender, isto facilita a implantação e operação de modelos de governança o que, em última instância, aumenta a possibilidade de lucro da organização, o que não deixa de ser o objetivo maior de todo acionista. Por tanto, é imperativo levar em consideração o que a corporação traz aos gestores intermediários e qual a razão de sua existência dentro da organização moderna. Além disso, os resultados desta pesquisa nos possibilitam considerar que a maioria dos gestores intermediários coloca como estratégia básica de desenvolvimento da carreira, o reconhecimento de suas competências por parte de seus pares, superiores e funcionários, como fundamentais para que possam atingir os objetivos corporativos propostos. Não por acaso, alguns entrevistados inclusive afirmaram adotar a estratégia de "roubar trabalho" de outros colegas, a fim de mostrar resultados ao superior e subir na hierarquia corporativa.

De modo mais específico, a interpretação do material empírico coletado mostra que a empresa norte- americana e a empresa multinacional brasileira possuem estruturas mais centralizadas do que a lusoespanhola-brasileira. Nesse sentido, as estratégias corporativas dos gestores intermediários das duas primeiras empresas sugerem que estes seguem as métricas estabelecidas pelos seus superiores e políticas corporativas, embora se valham do conhecimento e relacionamento local para auferir vantagens em relação aos concorrentes. Quanto à empresa luso-espanholabrasileira, aparentemente, os gestores intermediários conseguem graus de influência maiores, na medida em que a estratégia da empresa, fundamental para sua sobrevivência, é gerada a partir dos números e ações propostas pelos gestores intermediários. Por outro lado, os gestores intermediários da filial brasileira da empresa norte-americana e da matriz da multinacional brasileira são mais submissos do que seus colegas da empresa luso-espanhola-brasileira em relação à dimensão de controle.

Quanto à relação dos gestores intermediários com o poder e a mudança, dentro de organizações atuantes no Brasil, esta pesquisa reforça os seguintes desafios: a) ao serem eles próprios os modelos de referência, os gestores intermediários jogam com sua reputação na medida em que pedem para serem seguidos exatamente pela credibilidade construída em sua relação com o seu time operacional; b) continuar a manter sua área operando é outro aspecto que o gestor intermediário terá como responsabilidade, enquanto ocorrem as mudanças; c) desempenhar o papel de implantar as mudanças necessárias provavelmente provocará uma sobrecarga no trabalho do gestor intermediário; d) os gestores intermediários se confrontam com os desafios de acomodar um intenso regime de trabalho com muitas horas fora de casa e as pressões crescentes em relação ao seu comprometimento com a organização. Isto pode trazer um grande obstáculo às mulheres para a evolução de suas carreiras executivas, pois se observou que a presença de filhos tem efeito contrário sobre o regime de trabalho de homens e mulheres. Isto é, quando existem filhos, os homens tendem a aumentar sua jornada de trabalho e as mulheres tendem a reduzir sua jornada de trabalho.

Finalmente, a partir dos resultados obtidos com a realização desta pesquisa é possível concluir que: i) Nas três empresas investigadas, os gestores intermediários sugerem que aqueles que ocupam gerências consideradas estratégicas são os candidatos naturais para subir na hierarquia corporativa, sendo, para eles, algo natural buscarem estas posições para 
prosperarem na carreira; ii) As redes de relacionamento informais, constituídas pelos gestores intermediários, são mais poderosas, quando se valem das regras e políticas corporativas estabelecidas para benefício mútuo, tanto nos momentos bons quanto nos ruins e iii) As redes de relacionamento extracompanhia, para fortalecimento de posições e troca de favores, são fundamentais para manutenção do poder dos gestores intermediários, já que esta é uma estratégia mobilizada, corriqueiramente, para que eles assegurem a manutenção de suas posições sociais e recursos duramente conquistados.

\section{Agenda para Futuras Pesquisas}

Em face do recorte teórico, empírico e metodológico, sabemos que esta pesquisa possui limitações. Mas espera-se que as eventuais limitações sejam supridas ao ser reforçado, por meio das contribuições geradas neste artigo, estudos que avancem sobre perspectivas tais como: primeiro, pesquisas que avancem no conhecimento sobre como as estratégias de sobrevivência utilizadas pelos gestores intermediários no Brasil, constituem arranjos e nós organizacionais permeados por jogos de poder e que, portanto, são capazes de influenciar os processos de mudanças organizacionais. Segundo, a realização de estudos mais detalhados sobre as estratégias de poder de gestores intermediários em organizações de diferentes portes e inseridas em distintos setores de atuação, o que favorecerá a identificação de possíveis peculiaridades de um conjunto de estratégias de poder/sobrevivência em detrimento das circunstâncias e contexto organizacional no qual atuam gestores intermediários. $\mathrm{E}$, terceiro, a realização de investigações que visem, inspiradas nos resultados apresentados neste estudo, identificar possíveis ajustes e oportunidades que possam orientar o aperfeiçoamento do conhecimento sobre as estratégias de poder mobilizadas por gestores intermediários atuantes no contexto organizacional brasileiro.

\section{Referências}

AL-HAKIM, L. A. Y.; HASSAN, S. The Role of Middle Managers in Knowledge Management Implementation to Improve Organizational Performance in the Iraqi Mobile Telecommunication Sector. Interdisciplinary Journal of Contemporary Research in Business, Vol. 3, No. 5, pp. 949-966, 2011.

ANTUNES, R. Adeus ao trabalho? Ensaio sobre as metamorfoses e a centralidade no mundo do trabalho. 14ª . ed. São Paulo: Cortez, 2010.

ANTUNES, R. O Continente do Labor. São Paulo: Boitempo. 2011.

AZEVEDO, M. C. DE.; TONELLI, M. J.; SILVA, A. L. Contratos flexíveis de trabalho: diferentes perfis de trabalhadores qualificados brasileiros. Rev. Adm. (São Paulo) [online], Vol.50, No.3, pp. 277-291, 2015. doi: 10.5700/rausp1200.

BADHAM, R. J. Technology and the transformation of work. In: ACKROYD, S.; BAT'T, R.;

THOMPSON, P.; TOLBERT, P. (eds.), The Oxford Handbook of Work \& Organization, UK: Oxford University Press, 2006.

BALOGUN, J. Blaming the Middle to Harnessing its Potential: Creating Change Intermediaries, British Journal of Management, Vol. 14, No. 1, pp. 69-83, 2003.

BARLEY, S. R.; KUNDA, G. Contracting: A New Form of Professional Practice. Academy of Management Perspectives, Vol. 20, No. 1, pp. 4566, 2006.

BISELLI, F. F.; TONELLI, M. J.; SILVA, A. L. Caminante no hay caminho, se hace camino al andar: um estudo sobre a construção dos sentidos em estratégia, Iberoamerican Journal of Strategic Management, Vol. 14 No 4, pp. 7-23, 2015.

BLUHM, D. J.; HARMAN, W.; LEE, T. W.; MITCHELL, T. R. Qualitative Research in Management: A Decade of Progress", Journal of Management Studies, Vol. 48, pp. 1866-1891, 2011. doi: 10.1111/j.1467-6486.2010.00972.x

BRESSER-PEREIRA, L. C. The Rise of Middle Class and Middle Management in Brazil, Journal of InterAmerican Studies, Vol. 4, No. 3, pp. 313-326, 1962. 
BUSS, W. C.; KUYVENHOFEN, R. Perceptions of European Middle Managers of Their Role in Strategic Change. Global Journal of Business Research, Vol. 5, No. 5, pp. 109-119, 2011.

CALDAS, M. P. Enxugamento de Pessoal no Brasil: podem-se atenuar seus efeitos em empresa e indivíduo? Revista de Administração de Empresas, Vol. 40, No. 1, pp. 29-41, 2000.

CLEGG, S.; McAULEY, J. Conceptualizing Middle Management in Higher Education: a Multifaceted Discourse. Journal of Higher Education Policy \& Management, Vol. 27, No. 1, pp. 19-34, 2005.

CONWAY, E.; MONKS, K. Change from below: the role of middle managers in mediating paradoxical change. Human Resource Management Journal, Vol. 21, No. 2, pp. 190-203, 2011.

DEDECCA, C. S. Flexibilidade e regulação de um mercado de trabalho precário: a experiência brasileira. Anais... Colóquio Internacional de Novas Formas do Trabalho e Desemprego: Brasil, Japão e França numa Perspectiva Comparada, São Paulo, SP, Brasil, 1, 2006.

DOPSON, S.; NEUMANN, J. Uncertainty, Contrariness and the Double-Blind: Middle Managers Reactions to their Changing Contracts. British Journal of Manager, Vol. 9, No. spec, pp. 53-70, 1998.

DRUCKER, P. F. The coming of the new organization. Harvard Business Review, Vol. 68, No. 6, pp. 45-53, 1988.

DUARTE, M. F. de.; SILVA, A. L. A reconstrução da carreira em ambiente de trabalho em transformação, Organização \& Sociedade, Vol. 20 No 67, pp. 699715, 2013.

FLOYD, S. W.; WOOLDRIDGE, B. Middle Management's Strategic Influence and Organizational Performance. Journal of Management Studies, Vol. 34, No. 3, pp. 465-485, 1997.

FREITAS, M. E. O Day-After das Reestruturações: as Irracionalidades e a Coisificação do Humano. Rae Light, São Paulo, Vol. 6, No. 1, pp. 3-5, 1999.

GITAHY, L. Inovação tecnológica, subcontratação e mercado de trabalho. São Paulo em Perspectiva, Vol. 8, No. 1, pp. 144-153, 1994.
GUBA, E. G.; LINCOLN, Y. S. Competing paradigms in qualitative research. In: Denzin, Norman K.; Lincoln, Yvonna S. (eds.), Handbook of qualitative research. Thousand Oaks, CA: Sage, 1994.

HALLIER, J. Embellishing the Past: Middle Manager Identity and Informality in the Implementation of New Technology. New Technology, Work \& Employment, Vol. 19, No. 1, pp. 43-62, 2004.

HARVEY, D. A condição pós-moderna. São Paulo: Ed. Loyola, 1992.

HOLE, O. The Politics of Middle Management Sensemaking and Sensegiving. Journal of Change Management, Vol. 10, No. 2, pp. 195-215, 2010.

IANNI, O. O mundo do trabalho. São Paulo em Perspectiva, 8(1), 2-12, 1994.

JANCZAK, S. Middle Management: The Phoenix Phenomenon. Canadian Manager, Vol. 29, No. 3, pp. 22-25, 2004.

KALLEBERG, A. L. Nonstandard employment relations: part-time, temporary and contract work. Annual Review of Sociology, Vol. 26, No. 1, pp. 341-365, 2000.

KANTER, R. M. The Middle Manager as Innovator. Harvard Business Review, Vol. 82, No. 7/8, pp. 150-161, 2004.

KREMER, A.; FARIA, J. H. Reestruturação produtiva e precarização do trabalho: o mundo do trabalho em transformação. Revista de Administração da USP, Vol. 40, No. 3, pp. 266-279, 2005.

LASSEN, A. H.; WAEHRENS, B. V.; BOER, $\mathrm{H}$. Re-orienting the Corporate Entrepreneurial Journey: Exploring the Role of Middle Management. Creativity and Innovation Management, Vol. 18, N. 1, pp. 16-23, 2009.

LAVARDA, R. A. B.; CANET-GINER, M. T.; PERISBONET, F. J. How Middle Managers Contribute to Strategy Formation Process: Connection of Strategy Processes and Strategy Practices. Revista de Administração de Empresas, Vol. 50, No. 4, pp. 358-370, 2010.

LEE, G.; TEO, A. Organizational Restructuring: Impact on Trust and Work Satisfaction. Asian Pacific Journal of Management, Vol. 22, pp. 23-39, 2005.

LORSCH, J. W.; BAUGHMAN, J. P.; REECE, J.; 
MINTZBERG, H. Understanding management.

New York: Harper \& Row, 1978.

MERRIAM, S. B. Qualitative research in practice: examples for discussion and analysis. San Francisco: Jossey-Bass, 2002.

MILLS, D. Q. Ribirth of the corporation. New York: Wiley, 1991.

MINTZBERG, H. Mintzberg on Management: Inside our Strange World of Organizations. New York: The Free Press, 1989.

OUIMET, G. Estratégias de Poder e Atores Desprovidos de Recursos. Revista de Administração de Empresas, Vol. 43, No. 1, pp. 49-59, 2003.

PAPPAS, J. M. Middle Managers Strategic Influence: Investigating Network Centrality and Perceptual Deviance. Academy of Management Proceedings, C1-C6, 2004.

PAPPAS, J. M.; WOOLDRIDGE, B. Middle Managers' Divergent Strategic Activity: An Investigation of Multiple Measures of Network Centrality. Journal of Management Studies, Vol. 44, No. 3, pp. 323-341, 2007.

PETERSON, M. F. Role Conflict, Ambiguity and Overload: a 21-nation Study. Academy of Management Journal, Vol. 38, No. 2, pp. 429-452, 1995.

PINSONNEAULT, A.; KRAEMER, K. L. Middle ManagementDownsizing: an Empirical Investigation of the Impact of Information Technology. Management Science, Vol. 43, No. 5, pp. 659-679, 1997.

RAES, A. M. L.; HEIJLTJES, M. G.; GLUNK, U.; ROE, R. A. The interface of the top management team and middle managers: a process model. Academy of Management Review, Vol. 36, No. 1, pp. 102-126, 2011.

RUAS, R. Reestruturação Sócio-Econômica, Adaptação das Empresas e Gestão do Trabalho. In: Gitahy, Leda. (org.), Reestructuracion Productiva, Trabajo y Education en America Latina (Lecturas de education y trabajo $\mathbf{n}^{\mathbf{0}}$ 3), Campinas: IG/Unicamp, Buenos Aires, RED CIID-Cenep, 1994.

TACHIZAWA, T.; FERREIRA, V. C. P.; FORTUNA, A. A. M. Gestão com pessoas: uma abordagem aplicada às estratégias de negócios. 5 a Ed. Rio de Janeiro: Editora FGV, 2006.
UYTERHOEVEN, H. E. R. General Managers in the Middle. Harvard Business Review, Vol. 50, No. 2, pp. 75-85, 1972.

VALENTINO, C. L. The Role of Middle Managers in the Transmission and Integration of Organizational Culture. Journal of Healthcare Management, Vol. 49, No. 6, pp. 393-404, 2004.

WILLCOCKS, L.; GRIFFITHS, C. The Crucial Role of Middle Management in Outsourcing. Mis Quartely Executive, Vol. 9, No. 3, pp. 177-193, 2010.

WOOD, S. The Transformation of Work? Londres: British Council, 1989.

WOOD Jr, T. Mudança Organizacional. São Paulo: Atlas, 2004. 